\title{
Advancing the understanding of behavior in social-ecological systems: results from lab and field experiments
}

\author{
Marco A. Janssen ${ }^{1}$, Therese Lindahl ${ }^{2,3}$ and James J. Murphy ${ }^{4,5,6}$
}

Key Words: behavioral economics; common-pool resources; experimental economics; public goods; social-ecological systems

Experiments have made important contributions to our understanding of human behavior, including behavior relevant for understanding social-ecological systems. When there is a conflict between individual and group interests in socialecological systems, social dilemmas occur. From the many types of social-dilemma formulations that are used to study collective action, common-pool resource and public-good dilemmas are most relevant for social-ecological systems. Experimental studies of both common-pool resource and public-good dilemmas have shown that many predictions based on the conventional theory of collective action, which assumes rational, self-interested behavior, do not hold. More cooperation occurs than predicted (Ledyard 1995), "cheap talk" increases cooperation (Ostrom 2006), and participants are willing to invest in sanctioning free riders (Yamagishi 1986, Ostrom et al. 1992, Fehr and Gächter 2000, Chaudhuri 2011). Experiments have also demonstrated a diversity of motivations, which affect individual decisions about cooperation and sanctioning (see Fehr and Fischbacher 2002 and Sobel 2005 for reviews, and Bowles 2008 for policy implications).

In early experiments, the resource dilemma was typically described as a static situation and the focus was primarily on understanding the social interactions of participants under different institutional settings, e.g., rules for communication, punishment, and regulations. Most of these early experiments involved a series of independent rounds and did not include resource dynamics. In each round the participant faced the same decision problem. These static setups allowed researchers to observe and make inferences about how individual strategies, social interactions, and group outcomes changed over time as participants got more information about the behavior of the others. A few early experiments include dynamics of the resources, such as probabilistic destruction (Walker and Gardner 1992), and the dependence of extraction cost on decisions in previous rounds (Herr et al. 1992). These earlier studies, which focused on common-pool resource dilemmas, demonstrated that dynamics increased harvesting rates compared with the static setting.

However, most of the early experimental designs did not include important aspects of some of the challenges experienced by real resource users. For example, these designs often failed to capture how the biophysical context affects the spatial and temporal dynamics of the resource, the visibility of actions by others, and the power relationships between actors. Thus, an institutional arrangement that works effectively for one resource problem might be a dismal failure if applied to another resource problem (Acheson 2006). For example, factors such as whether the resource units are mobile (e.g., fishery, pastoralism) or whether infrastructure is developed to guide the resource flow (e.g., irrigation systems) have been identified as important attributes of resources affecting behavior in these dilemmas (Schlager et al. 1994, Janssen et al. 2007). This indicates that an understanding of human behavior in social dilemmas needs to include not only relevant aspects of relationships among humans, but also how people interact with the temporal and spatial dynamics of the resource.

In recent years, there has been an increased effort to address this issue with controlled experiments that incorporate relevant ecological characteristics of these social-ecological systems (Janssen et al. 2010, Knapp and Murphy 2010, McAllister et al. 2011, Cárdenas et al. 2013, Kimbrough and Wilson 2013). In this new generation of experiments, there is a specific emphasis on including various relevant additional complexities of the socialecological context, such as thresholds, disturbances, asymmetries, and spatial heterogeneity. This Special Feature brings together a collection of research papers that provides an overview of this emerging field. The collection comes from a workshop on this topic held at Arizona State University in March 2013. The papers present an overview of the findings of experiments held in both the lab and the field.

The authors of the papers in this Special Feature have backgrounds in various disciplines, including ecology and economics. This interdisciplinary nature of the scholars has led to new designs and different types of software used to run experiments. Janssen et al. (2014) reviewed a number of experimental platforms relevant for scholars who want to use experimental methods for the study of social-ecological systems. Platforms differ in their ability to include complexity and the userfriendliness to implement and run experiments. Some platforms, including pencil and paper, can be used to run basic experiments, but the inclusion of more complex ecological dynamics requires specific software for which more sophisticated programming experience is needed. Janssen et al. provided a detailed set of criteria that may help future experimentalists to decide which of the platforms to use.

We first discuss a series of papers using laboratory experiments that included different ways to increase relevant social and biophysical complexity. Hillis and Lubell (2015) present an intergenerational public-good experiment in which groups were not independent. Based on the notion of cultural transmission, at the start of the experiment the group members received advice from earlier groups who had played the experiment. Furthermore, at the end of the experiment they were allowed to leave advice for

${ }^{1}$ Arizona State University, ${ }^{2}$ Beijer Institute of Ecological Economics, Royal Swedish Academy of Science, ${ }^{3}$ Stockholm Resilience Centre, Stockholm University, ${ }^{4}$ Nankai University, ${ }^{5}$ University of Alaska Anchorage, ${ }^{6}$ Chapman University 
future groups. Besides varying whether groups could leave messages for future participants and receive messages from those who have already participated, treatments also varied whether they could communicate within the experiment itself. The results showed that the combination of communication during the experiment and intergenerational messages led to substantially higher levels of cooperation compared with no communication and no messages.

Kreitmair (2015) also used a public-good experiment in which participants could voluntarily share information about their actions. She found that voluntary information sharing led to higher levels of cooperation than both a no-disclosure baseline and mandatory information disclosure. The voluntary disclosure of information may be particularly useful when enforcement is costly.

Schill et al. (2015) studied a common-pool resource dilemma and varied another component of the experiment, namely, the ecological dynamics of the resource. They looked at a resource that can experience regime shifts in productivity, depending on the level of extraction. In all treatments, participants were able to communicate with each other at any time, not just between rounds, as is common in many experiments. Their results suggested that the higher the probability of such a latent shift, the more likely the group was to be cautious. The groups had higher levels of collective action when risks were higher.

Cherry et al. (2015) studied the effect of shocks on the willingness of participants to share resources with the affected individual. The experiment was inspired by many situations in Arctic communities where individuals can lose their resource because of external events. Cherry et al. found that even without a commitment to pool resources, participants voluntarily pooled risk, thereby reducing the variability of individual earnings.

Baggio et al. (2015) found that higher risks did not have a major impact on the decisions of participants. They studied irrigation dilemmas in which participants had asymmetric access to withdraw from the common resource while every participant could make a contribution to the production of the resource. Unlike participants in the Schill et al. (2015) experiment, participants in Baggio et al. (2015) experiment could not communicate, which might explain the lack of change in collective action for different levels of risk. Baggio et al. (2015) showed the importance of trust and inequality in explaining the observed actions of the participants. Those with higher trust levels invested more in the public infrastructure, and if the inequality of extractions in the group was not higher, the investment levels would not drop.

Like Baggio et al. (2015), Pérez et al. (2015) also studied irrigation dilemmas in which subjects could communicate. Communication was allowed via the exchange of text messages, and they analyzed the transcripts to determine the social roles participants played during the experiment. The study showed that no single role, such as a leader or a connector, was sufficient for a cooperative outcome. Instead, they found that the combination of certain roles determined whether the group was successful.

Lab experiments are attractive in the sense that they provide the researcher with a "clean test tube" that provides control over contextual variables and facilitates causal inferences. Because they are conducted with students as participants, various complex designs are relatively easy and cheap to test. However, the potential drawback of lab experiments is precisely that they use student participants instead of "real" resource users (Cárdenas and Ostrom 2004). To which extent experimental results can be generalized beyond the lab is of course an important question that has received much attention recently (e.g., Levitt and List 2007, Falk and Heckman 2009, Henrich et al 2010, Fréchette and Schotter 2015, part IV). One way to address this question is to run experiments in the field with nonstudent populations as participants. Javaid and Falk (2015) conducted irrigation dilemma experiments in irrigation communities in Pakistan. Consistent with Kreitmar (2015), public information about each user's extraction decisions led to higher levels of cooperation. Moreover, Javaid and Falk (2015) showed that external sanctions reduced the efficiency of group outcomes.

Bell et al. (2015) also performed irrigation experiments with farmers in Pakistan and included interactions between surface and groundwater supplies. They found that better information about water flows reduced social disapproval, but it did not reduce inequality among the participants.

García-Barrios et al. (2015) described a set of role-playing experiments they conducted with both farmers and academics in Chiapas, Mexico. The experiment was a spatial game on land use change, i.e., pastoralism and deforestation. The study found differences in the social preferences between the two subject types. The academics mainly focused on coalition formation, whereas farmers were more competitive.

\section{Responses to this article can be read online at: http://www.ecologyandsociety.org/issues/responses. $\mathrm{php} / 8097$}

\section{Acknowledgments:}

We acknowledge financial support from the Biosocial Complexity Initiative at Arizona State University and from the National Science Foundation (Grant GEO-1115054).

\section{LITERATURE CITED}

Acheson, J. M. 2003. Capturing the commons: devising institutions to manage the Maine lobster industry. University Press of New England, Hanover, New Hampshire, USA.

Baggio, J. A., N. D. Rollins, I. Pérez, and M. A. Janssen 2015. Irrigation experiments in the lab: trust, environmental variability and collective action. Ecology and Society 20(4):12. http://dx.doi. org/10.5751/es-07772-200412

Bell, A. R., M. A. A. Shah, A. Anwar, and C. Ringler. 2015. What role can information play in improved equity in Pakistan's irrigation system? Evidence from an experimental game in Punjab. Ecology and Society 20(1):51. http://dx.doi.org/10.5751/ ES-07368-200151

Bowles, S. 2008. Policies designed for self-interested citizens may undermine "the moral sentiments": evidence from economic experiments. Science 320:1605-1609. http://dx.doi.org/10.1126/ science. 1152110 
Cárdenas, J.-C., M. A. Janssen, and F. Bousquet. 2013. Dynamics of rules and resources: three new field experiments on water, forests and fisheries. Pages 319-345 in J. A. List and M. K. Price, editors. Handbook on experimental economics and the environment. Edward Elgar, Cheltenham, UK. http://dx.doi. org/10.4337/9781781009079.00020

Cárdenas, J.-C., and E. Ostrom 2004. What do people bring into the game? Experiments in the field about cooperation in the commons. Agricultural Systems 82:307-326. http://dx.doi. org/10.1016/j.agsy.2004.07.008

Chaudhuri, A. 2011. Sustaining cooperation in laboratory public goods experiments: a selective survey of the literature. Experimental Economics 14:47-83. http://dx.doi.org/10.1007/ s10683-010-9257-1

Cherry, T. L., E. L. Howe, and J. J. Murphy. 2015. Sharing as risk pooling in a social dilemma experiment. Ecology and Society 20 (1):68. http://dx.doi.org/10.5751/ES-07390-200168

Falk, A., and J. J. Heckman. 2009. Lab experiments are a major source of knowledge in the social sciences. Science 326 (5952):535-538. http://dx.doi.org/10.1126/science.1168244

Fehr, E., and U. Fischbacher. 2002. Why social preferences matter - the impact of non-selfish motives on competition, cooperation and incentives. Economic Journal 112:C1-C33. http://dx.doi. org/10.1111/1468-0297.00027

Fehr, E., and S. Gächter. 2000. Fairness and retaliation: the economics of reciprocity. Journal of Economic Perspectives 14:159-181. http://dx.doi.org/10.1257/jep.14.3.159

Fréchette, G.R. and Schotter, A. 2015. Handbook of experimental economic methodology. Oxford University Press, New York, New York, USA. http://dx.doi.org/10.1093/acprof:oso/978019532832$\underline{5.001 .0001}$

García-Barrios, L., R. García-Barrios, J. Cruz-Morales, and J. A. Smith. 2015. When death approaches: reverting or exploiting emergent inequity in a complex land-use table-board game. Ecology and Society 20(2):13. http://dx.doi.org/10.5751/ ES-07372-200213

Herr, A., R. Gardner, and J. M. Walker. 1997. An experimental study of time-independent and time-dependent externalities in the commons. Games and Economic Behavior 19(1):77-96. http:// dx.doi.org/10.1006/game.1997.0541

Henrich, J., S. J. Heine, and A. Norenzayan. 2010. The weirdest people in the world. Behavioral and Brain Sciences 33(2-3):61-83. http://dx.doi.org/10.1017/S0140525X0999152X

Hillis, V., and M. Lubell. 2015. Breeding cooperation: cultural evolution in an intergenerational public goods experiment. Ecology and Society 20(2):8. http://dx.doi.org/10.5751/ES-07424-200208

Janssen, M. A., J. M. Anderies, and E. Ostrom. 2007. Robustness of social-ecological systems to spatial and temporal variability. Society \& Natural Resources 20(4):307-322. http://dx.doi. org/10.1080/08941920601161320

Janssen, M. A., R. Holahan, A. Lee, and E. Ostrom. 2010. Lab experiments for the study of social-ecological systems. Science 328:613-617. http://dx.doi.org/10.1126/science.1183532
Janssen, M. A., A. Lee, and T. M. Waring. 2014. Experimental platforms for behavioral experiments on social-ecological systems. Ecology and Society 19(4):20. http://dx.doi.org/10.5751/ ES-06895-190420

Javaid, A., and T. Falk. 2015. Incorporating local institutions in irrigation experiments: evidence from rural communities in Pakistan. Ecology and Society 20(2):28. http://dx.doi. org/10.5751/ES-07532-200228

Kimbrough, E. O., and B. J. Wilson. 2013. Insiders, outsiders, and the adaptability of informal rules to ecological shocks. Ecological Economics 90:29-40. http://dx.doi.org/10.1016/j.ecolecon.2013.02.008

Knapp, G., and J. J. Murphy. 2010. Voluntary approaches to transitioning from competitive fisheries to rights-based management: bringing the field into the lab. Agricultural and Resource Economics Review 39(2):245-261.

Kreitmair, U. 2015. Voluntary disclosure of contributions: an experimental study on nonmandatory approaches for improving public good provision. Ecology and Society 20(4):33. http://dx. doi.org/10.5751/ES-08004-200433

Ledyard, J. O. 1995. Public goods: a survey of experimental research. Pages 111-194 in J. H. Kagel and A. E. Roth, editors. The handbook of experimental economics. Princeton University Press, Princeton, New Jersey, USA.

Levitt, S. D., and J. A. List. 2007. What do laboratory experiments measuring social preferences reveal about the real world? Journal of Economic Perspectives 21(2):153-174. http://dx.doi.org/10.1257/ jep.21.2.153

McAllister, R. R. J., J. G. Tisdell, A. F. Reeson, and I. J. Gordon. 2011. Economic behavior in the face of resource variability and uncertainty. Ecology and Society 16(3):6. http://dx.doi. org/10.5751/ES-04075-160306

Ostrom, E. 2006. The value-added of laboratory experiments for the study of institutions and common-pool resources. Journal of Economic Behavior \& Organization 61:149-163. http://dx.doi. org/10.1016/j.jebo.2005.02.008

Ostrom, E., J. Walker, and R. Gardner. 1992. Covenants with and without a sword: self-governance is possible. American Political Science Review 86(2):404-417. http://dx.doi.org/10.2307/1964229

Pérez, I., D. J. Yu, M. A. Janssen, and J. M. Anderies. 2015. Social roles and performance of social-ecological systems: evidence from behavioral experiments. Ecology and Society 20(3):23. http://dx. doi.org/10.5751/es-07493-200323

Schill, C., T. Lindahl, and A.-S. Crépin. 2015. Collective action and the risk of ecosystem regime shifts: insights from a laboratory experiment. Ecology and Society 20(1):48. http://dx.doi. org/10.5751/ES-07318-200148 http://dx.doi.org/10.5751/ES-07318-200148

Schlager, E., W. Blomquist, and S. Y. Tang. 1994. Mobile flows, storage, and self-organized institutions for governing commonpool resources. Land Economics 70:294-317. http://dx.doi. org/10.2307/3146531

Sobel, J. 2005. Interdependent preferences and reciprocity. Journal of Economic Literature 43:392-436. http://dx.doi. org/10.1257/0022051054661530 
Yamagishi, T. 1986. The provision of a sanctioning system as a public good. Journal of Personality and Social Psychology 51 (1):110-116. http://dx.doi.org/10.1037/0022-3514.51.1.110

Walker, J. M., and R. Gardner.1992. Probabilistic destruction of common-pool resources: experimental evidence. Economic Journal 102:1149-1161. http://dx.doi.org/10.2307/2234382 